\title{
Serum CD26 is related to histopathological polyp traits and behaves as a marker for colorectal cancer and advanced adenomas
}

\author{
Loretta De Chiara†1, Ana M Rodríguez-Piñeiro+1, Francisco J Rodríguez-Berrocal1', Oscar J Cordero2, David Martínez- \\ Ares $^{3}$ and María Páez de la Cadena*1
}

\begin{abstract}
Background: Serum CD26 (sCD26) levels were previously found diminished in colorectal cancer (CRC) patients compared to healthy donors, suggesting its potential utility for early diagnosis. Therefore we aimed to estimate the utility of the sCD26 as a biomarker for CRC and advanced adenomas in a high-risk group of patients. The relationship of this molecule with polyp characteristics was also addressed.

Methods: SCD26 levels were measured by ELISA in 299 symptomatic and asymptomatic patients who had undergone a colonoscopy. Patients were diagnosed as having no colorectal pathology, non-inflammatory or inflammatory bowel disease, polyps (hyperplastic, non-advanced and advanced adenomas) or CRC.

Results: At a $460 \mathrm{ng} / \mathrm{mL}$ cut-off, the sCD26 has a sensitivity and specificity of $81.8 \%$ (95\% Cl, $64.5-93.0 \%$ ) and $72.3 \%$ (95\% Cl, 65.0-77.2\%) for CRC regarding no or benign colorectal pathology. Clinicopathological analysis of polyps showed a relationship between the SCD26 and the grade of dysplasia and the presence of advanced adenomas. Hence, a 58.0\% (95\% Cl, 46.5-68.9\%) sensitivity detecting CRC and advanced adenomas was obtained, with a specificity of $75.5 \%(95 \% \mathrm{Cl}, 68.5-81.0 \%)$.

Conclusions: Our preliminary results show that measurement of the sCD26 is a non-invasive and reasonably sensitive assay, which could be combined with others such as the faecal occult blood test for the early diagnosis and screening of CRC and advanced adenomas. Additional comparative studies in average-risk populations are necessary.
\end{abstract}

\section{Background}

Colorectal cancer (CRC) is one of the four most prevalent cancers in Western countries due to a low recovery rate in advanced stages, when micrometastases may be already present. It develops from precancerous lesions (adenomas) that are easily removed by polypectomy, a procedure that reduces CRC incidence by $75-90 \%$ [1]; moreover, treatment of early diagnosed tumours has a good prognosis [2]. Furthermore, according to the MISCAN-COLON simulation model, a $23 \%$ reduction in CRC mortality would be achieved with the screening of at least $70 \%$ of the target population [3]. Therefore screening for CRC aims to reduce mortality rates by detection

\footnotetext{
* Correspondence: mpaez@uvigo.es

1 Universidad de Vigo. Facultad de Biología. Departamento de Bioquímica, Genética e Inmunología. As Lagoas-Marcosende s/n. 36310 Vigo, Spain + Contributed equally

Full list of author information is available at the end of the article
}

and removal of early-stage tumours, and incidence rates by identification and resection of polyps [4].

There is a great variety of methods for the detection of $\mathrm{CRC}$. A review of the ongoing screening initiatives worldwide was recently published [5]. The latest Joint Colorectal Cancer Screening Guidelines [6] divide the available tests into two categories: those primarily aimed to detect cancer (blood and DNA stool tests), and those directed to detect also advanced lesions (endoscopic and radiographic methods).

Within the available invasive tests are the flexible sigmoidoscopy, the double-contrast barium enema and the colonoscopy. The latter is recommended nowadays as the gold standard, though its miss rates have been estimated as $22 \%$ for adenomas and 2-6\% for CRC [7]. However, bowel preparation constitutes the most objectionable aspect of the procedure, fundamental for a proper 
screening colonoscopy [8]. Other limitations of the colonoscopy are the risk of complications, the costs, and access. Regarding non-invasive tests, the most common method, nowadays recommended for CRC screening, is the guaiac faecal occult blood test (gFOBT), with highly variable and brand-dependent sensitivities and specificities $[6,9]$ and requiring dietary restrictions.

Thus there is an imperative need for developing noninvasive screening tests for the detection of CRC and adenomas, and hence many current studies are evaluating serum markers. Examples of these are the $\alpha$-defensins [10], the nicotinamide N-methyltransferase [11], the $\alpha$-Lfucosidase [12], or the colon cancer-specific antigens (CCSA) -2, -3 and $-4[13,14]$. A major drawback in these studies is they are limited to discriminating between CRC patients and healthy individuals, leaving aside precursor lesions and not including in the control cohort individuals with benign pathologies.

Previous studies of our group detected that soluble serum CD26 (sCD26) levels were diminished in CRC patients as compared to healthy donors $[15,16]$. In those studies, a sCD26 cut-off of $410 \mathrm{ng} / \mathrm{mL}$ demonstrated a $90 \%$ diagnostic efficiency, with a specificity and sensitivity of $90 \%$ as well [15]. This high diagnostic efficiency, even in early tumour stages, suggested its potential utility for diagnosis. Thus we considered of interest to extend the validation of the sCD26 as an early biomarker for $\mathrm{CRC}$, including also precancerous lesions (adenomas). One of the novelties of the study is the use of a colonoscopically healthy cohort instead of a blood donor cohort as the control population. Moreover, this is the first time the sCD26 is analyzed regarding the clinicopathological characteristics of colorectal polyps. Thus, we aim to analyse the relationship of the serum CD26 levels with the colonoscopic findings, in order to validate the utility of this protein as a marker for CRC diagnosis.

\section{Methods \\ Population}

The population studied consisted of patients from the CHUVI hospital (Complejo Hospitalario Universitario de Vigo; Spain) who had undergone colonoscopy at the Gastroenterology Department. All the procedures described were performed according to the clinical ethical practices of the Spanish Government. The study was approved by the Galician Ethical Committee for Clinical Research (2002/059) and complied with the tenets of the Helsinki Declaration, the Oviedo Agreement, the Organic Law for Data Protection 15/1999 and the Royal Decree 1720/ 2007. Anonymity was warranted through the use of clinical history numbers. For patients willing to be included in the study, informed consent was obtained and blood was extracted. The only exclusion criterion was a non-completed colonoscopy (understood as completed when the caecum was reached). The 299 patients included were both males and females, with ages ranging from 18 to 93 years. Clinical histories were recorded, including symptoms of bowel disease, personal history of polyps, CRC and other cancers, family history of cancer, and colonoscopy indication. This was mostly due to symptoms as rectal bleeding (35.5\%), abdominal pain (10\%), diarrhoea (9\%), constipation $(5.7 \%)$, anaemia (5\%), but also for colorectal polyp (12.7\%) or cancer (4.3\%) surveillance, or CRC screening (12.4\%). All procedures were blinded.

Based on the histological report, patients were classified into: no colorectal pathology, non-inflammatory bowel disease (non-IBD), inflammatory bowel disease (IBD), polyps and CRC; polyps were sub-classified as hyperplastic or adenomas. Advanced adenomas were defined as those larger than $10 \mathrm{~mm}$, with tubulovillous or villous histology, or with high-grade dysplasia. Patients with more than one polyp were classified according to the most advanced lesion. CRC patients were classified according to Dukes' staging. No carcinomas in situ were detected in the patients included in the study.

\section{Collection of blood samples and determination of the sCD26 levels}

Blood samples were collected, coagulated at room temperature for $20 \mathrm{~min}$, and centrifuged at 2,000 $\mathrm{g} 15 \mathrm{~min}$. Sera were stored at $-80^{\circ} \mathrm{C}$. The sCD26 concentration was measured with the sCD26 ELISA kit (Bender Medsystems; Vienna, Austria) according to the manufacturer's instructions. Colorimetric quantification was performed with a microplate reader (model 550; Bio-Rad, USA) at $450 / 570 \mathrm{~nm}$.

\section{Statistical analysis}

Statistical analyses were performed with the SPSS package (v16.0); tests were two-sided; $p$-values $<0.05$ were considered significant. Normal distributions and homogeneity of variances were verified by KolmogorovSmirnov and Levene';s tests, respectively. Analysis of two independent samples was done by Mann-Whitney's $U$, whereas for more samples we employed the Kruskal-Wallis test. Chi-square or Fischer's exact tests were done with contingency tables, and applied for analyses regarding positivity/negativity of the sCD26. Bonferroni, false discovery rate (FDR) and SGoF tests were subsequently performed with the SGoF metatest software to correct for multiple comparison [17]. The sCD26 ability to separate healthy from diseased patients was studied by receiver operating characteristic (ROC) curves. Sensitivity and specificity were calculated using MedCalc (v.10.0.2). 


\section{Results}

sCD26 levels according to the colonoscopic results

According to the colonoscopic diagnosis, the 299 patients were classified as 68 patients with no colorectal pathology (symptomatic with rectal bleeding, abdominal pain, diarrhoea, anaemia, constipation, or asymptomatic with personal history of polyps or CRC, and family history of polyps); 64 patients with non-IBD (haemorrhoids and diverticula); 26 patients with IBD (colitis or Crohn's disease); 108 patients with colorectal polyps (hyperplastic polyps, non-advanced adenomas and advanced adenomas); and 33 patients with CRC.

As shown in table 1, the average sCD26 level for the 6 groups with no colorectal pathology was $641.2 \pm 241.2$ $\mathrm{ng} / \mathrm{mL}$; individuals with anaemia showed a considerably low sCD26 mean $(370.8 \pm 144.7 \mathrm{ng} / \mathrm{mL})$, statistically different from other non-colorectal pathology patients $(U$ test $p=0.001)$. Regarding patients with colorectal pathology, the non-IBD group exhibited mean sCD26 levels similar to the non-colorectal pathology group (612.2 \pm $231.0 \mathrm{ng} / \mathrm{mL}$ ). In contrast, patients with IBD showed lower values with relatively more variation (434.4 \pm 239.7 $\mathrm{ng} / \mathrm{mL}$ ). Patients diagnosed as having polyps (both hyperplastic and adenomas) resulted in an intermediate mean sCD26 concentration (588.0 $\pm 246.5 \mathrm{ng} / \mathrm{mL})$, while patients with CRC registered the lowest levels (403.7 \pm $278.2 \mathrm{ng} / \mathrm{mL}$ ).

The Kolmogorov-Smirnov test demonstrated, except for the CRC population ( $p=0.035)$, a normal distribution of the sCD26 concentration for all the groups. When the levels of sCD26 were compared among all the five groups of patients, we found significant differences (KruskalWallis test $p<0.001)$. Moreover, this differences were not related to gender ( $U$ test $p=0.219)$ or age $(\leq 50$ years or $>$ 50 years; $U$ test $p=0.109)$, as reported in a large cohort study [18].

\section{ROC curve and SCD26 positivity}

To evaluate the utility of the SCD26 as a tumour marker, we estimated a cut-off to differentiate the CRC group (33 patients) from the control population (68 patients with no colorectal pathology). First we constructed the ROC curve, which resulted in an area of 0.811 (95\% CI, 0.721$0.882 ; p<0.0001)$. On the basis of this plot, table 2 shows four different potential cut-off values with their respective sensitivity and specificity. Sensitivity for CRC almost reached $85 \%$ at the cut-off of $500 \mathrm{ng} / \mathrm{mL}$, but with a specificity below $75 \%$; when specificity was raised up to $83.8 \%$ at $390 \mathrm{ng} / \mathrm{mL}$, sensitivity resulted in a $57.6 \%$. The cut-off value with the highest average diagnostic performance was $460 \mathrm{ng} / \mathrm{mL}$, showing a sensitivity of $81.8 \%$ (95\% CI, 64.5-93.0\%) with a specificity of $79.4 \%$ (95\% CI, 67.9$88.3 \%)$.

A positive $\mathrm{sCD} 26$ value was therefore $\leq 460 \mathrm{ng} / \mathrm{mL}$ (figure 1$)$. The positivity rate increased from $20.6 \%(14 / 68)$ in the non-colorectal pathology group to $81.8 \%(27 / 33)$ in the CRC group. Patients with non-IBD, IBD, hyperplastic polyps, non-advanced adenomas and advanced adenomas showed intermediate rates, corresponding to $28.1 \%$ (18/64), 69.2\% (18/26), 22.2\% (4/18), $22.5 \%$ (9/40) and $41.7 \%(20 / 48)$, respectively.

\section{Relationship between the sCD26 and the clinicopathological features of polyps}

We analysed the relationship of the sCD26 with the histopathological characteristics of the colorectal polyps found by colonoscopy (table 3), including: number of polyps $(1-2,3$ or more); size $(\leq 0.5 \mathrm{~cm}, 0.6-1 \mathrm{~cm},>1 \mathrm{~cm})$; location (rectum, sigma, left colon, transverse colon, right colon); morphology (sessile, pediculated, flat); histology (hyperplasic, adenoma) and detailed histology (hyperplastic, tubular, villous, tubulovillous); grade of dysplasia (absence, low-grade, high-grade); and presence of advanced adenomas. The histology for two polyps was missing. The variables gender and age $(\leq 50$ and $>50$ years) were also studied, confirming no statistical differences in relation to the $\mathrm{sCD} 26$ positivity $(p=0.212$ and $p$ $=0.132$, respectively)

The Chi-square tests revealed no statistical differences regarding the number of polyps, their size, location, morphology or histology. Differences close to significant were observed between the sCD26 positivity and the grade of dysplasia $(p=0.056)$. The positivity rate increased gradually while the degree of dysplasia became more severe: $22.2 \%$ for non-dysplastic polyps, $32.5 \%$ for low-grade dysplastic adenomas and almost double (60.0\%) for highgrade dysplastic adenomas. When comparing the sCD26 positivity rate of the advanced and non-advanced adenomas populations, statistically significant differences were detected $(p=0.048)$. Bonferroni, FDR and SGoF post-hoc tests were not significant for any of these analyses.

Finally, diagnostic parameters were calculated for the detection of advanced adenomas and CRC, with the control group including all the remaining cohorts (table 4). At the $460 \mathrm{ng} / \mathrm{mL}$ cut-off, sensitivity resulted in $58.0 \%$ (95\% CI, 46.5-68.9\%), with a specificity of $75.5 \%$ (95\% CI, 68.5-81.0\%). When these parameters were calculated for the detection of only CRC patients, the sensitivity increased to $81.8 \%$ (95\% CI, 64.5-93.0\%) whereas the specificity was just slightly diminished to $72.3 \%$ (95\% CI, 65.0-77.2\%). This value increased to $90 \%$ (95\% CI, 73.4$97.8 \%$ ) if the specificity was calculated for the non-symptomatic group versus the CRC group.

\section{Discussion}

The glycoprotein CD26 or dipeptidyl peptidase IV (DPPIV, E.C. 3.4.14.5) is an exopeptidase of the plasma membrane able to release dipeptides from the $N$-terminal end of peptides/proteins bearing proline or alanine in the 
Table 1: Average SCD26 concentration for the groups studied according to the colonoscopy result.

\begin{tabular}{|c|c|c|c|c|}
\hline \multirow[t]{2}{*}{$\begin{array}{l}\text { No colorectal } \\
\text { pathology }\end{array}$} & \multirow{2}{*}{$\begin{array}{l}\text { Clinical condition } \\
\text { Rectal bleeding }\end{array}$} & \multirow{2}{*}{$\begin{array}{l}n \\
8\end{array}$} & \multicolumn{2}{|c|}{$\begin{array}{c}\text { Mean } \pm \\
\text { SD sCD26 }(\mathrm{ng} / \mathrm{mL})\end{array}$} \\
\hline & & & $651.5 \pm 190.2$ & \multirow{6}{*}{$641.2 \pm 241.2$} \\
\hline & Abdominal pain & 10 & $586.1 \pm 194.4$ & \\
\hline & Diarrhoea & 9 & $649.5 \pm 306.8$ & \\
\hline & Anaemia & 7 & $370.8 \pm 144.7$ & \\
\hline & Constipation & 4 & $782.7 \pm 194.6$ & \\
\hline & No symptoms* & 30 & $698.5 \pm 234.2$ & \\
\hline $\begin{array}{l}\text { Colorectal } \\
\text { pathology }\end{array}$ & Diagnosis & $n$ & \multicolumn{2}{|c|}{$\begin{array}{c}\text { Mean } \pm \text { SD } \\
\text { SCD26 }(\mathrm{ng} / \mathrm{mL})\end{array}$} \\
\hline Non-inflammatory & Haemorrhoids & 36 & $655.3 \pm 240.4$ & \multirow{3}{*}{$612.2 \pm 231.0$} \\
\hline bowel disease & & & & \\
\hline (non-IBD) & Diverticula & 28 & $556.7 \pm 209.6$ & \\
\hline Inflammatory & Colitis & 20 & $413.2 \pm 195.5$ & \multirow{3}{*}{$434.4 \pm 239.7$} \\
\hline bowel disease & & & & \\
\hline (IBD) & Crohn's disease & 6 & $505.1 \pm 355.8$ & \\
\hline & Hyperplastic polyps & 18 & $560.4 \pm 201.3$ & \multirow{3}{*}{$588.0 \pm 246.5$} \\
\hline \multirow[t]{4}{*}{ Polyps } & Non-advanced adenomas & 40 & $611.1 \pm 263.8$ & \\
\hline & Advanced adenomas & 48 & $566.7 \pm 225.8$ & \\
\hline & Duke's A & 2 & $513.9 \pm 240.4$ & \multirow{5}{*}{$403.7 \pm 278.2$} \\
\hline & Duke's B & 12 & $369.8 \pm 147.4$ & \\
\hline \multirow[t]{3}{*}{$C R C$} & & & & \\
\hline & Duke's C & 15 & $402.0 \pm 360.3$ & \\
\hline & Duke's D & 4 & $457.0 \pm 323.0$ & \\
\hline
\end{tabular}

SD: standard deviation of the mean; *: personal history of polyps or CRC, or familial history of CRC.

penultimate position [19]. Biological fluids contain relatively high levels of sCD26, which is presumably shed by proteolytic cleavage from any cell expressing transmembrane CD26 [20]. Although its origin is still unclear, the liver and the $\mathrm{T}$ cells are cited as the most likely sources [21].

The measurement of the sCD26 levels was performed in serum from individuals whom, due to different medical indications, had undergone colonoscopy; most of them referred abdominal, colon or rectal symptoms, or famil$\mathrm{ial} /$ personal history of polyps or CCR. The individuals without colorectal findings after the colonoscopy were considered as the control cohort; the remaining were classified as: non-IBD, IBD, colorectal polyps or CRC patients. The mean sCD26 concentration decreased, although non-significantly, as the pathology diagnosed 
Table 2: Sensitivity and specificity of the SCD26 at different cut-off values for separating individuals with no colorectal pathology from those with CRC.

\begin{tabular}{ccccc}
\hline Cut-off (ng/mL) & Sensitivity (95\% Cl) & Specificity (95\% Cl) & +LR & -LR \\
\hline $\mathbf{3 9 0}$ & $57.6 \%(38.2-74.5)$ & $83.8 \%(72.9-91.6)$ & 3.6 & 0.5 \\
\hline $\mathbf{4 1 0}$ & $72.7 \%(54.5-86.7)$ & $80.9 \%(69.5-89.4)$ & 3.8 & 0.3 \\
\hline $\mathbf{4 6 0}$ & $81.8 \%(64.5-93.0)$ & $79.4 \%(67.9-88.3)$ & 4.0 & 0.2 \\
\hline $\mathbf{5 0 0}$ & $84.9 \%(68.1-94.8)$ & $72.1 \%(59.9-82.3)$ & 3.0 & 0.2 \\
\hline
\end{tabular}

+LR: Positive likelihood ratio; -LR: Negative likelihood ratio.

was more severe (as seen in table 1), this is, from no colorectal pathology to $\mathrm{CRC}$, with a noticeable decrease in the group with IBD.

In our previous study, the control cohort was formed exclusively by healthy donors [15], whereas in the present study it was formed by individuals with confirmed no colorectal pathology but bearing symptoms, or with history of polyps or cancer. Thus we calculated a new cut-off of $460 \mathrm{ng} / \mathrm{mL}$, higher than the value of $410 \mathrm{ng} / \mathrm{mL}$ reported for healthy donors [15].

According to this cut-off, within the no colorectal pathology group, individuals with anaemia showed a substantially elevated positivity rate $(71.4 \%)$ as expected from their mean levels. Non-IBD exhibited a low positivity rate $(28.1 \%)$, whereas the IBD group reached $73.1 \%$. This pathology is associated with at least a 5-fold increased risk for CRC, representing one of the highest risk groups based on the inflammation-dysplasia-carcinoma sequence [22]. In compliance with this sequence, the $\mathrm{sCD} 26$ positivity rate increased from no colorectal pathology to hyperplastic polyps and non-advanced ade- nomas, with a further increase in advanced adenomas and CRC.

The capability of colorectal polyps to develop into cancer is related to the size of the lesion, the proportion of villous component and the grade of dysplasia. In relation to dysplasia, a morphological marker of neoplastic lesions, we observed a direct (positive) trend between the grade of dysplasia and the positivity of the biomarker, though there was no significant correlation between both parameters. Concerning advanced adenomas, a term commonly used to group adenomas that have an increased likelihood of malignant transformation, the sCD26 positivity resulted statistically significant.

Recent works also studied other potential markers in relation to polyp characteristics: for the serum sulfatase activity, differences regarding the number of adenomas (single or multiple) were significant [23]; serum leptin, adiponectin and resistin also differed between controls and patients with adenomas or CRC, though there was no relationship with dysplasia, histopathology or polyp localization [24].

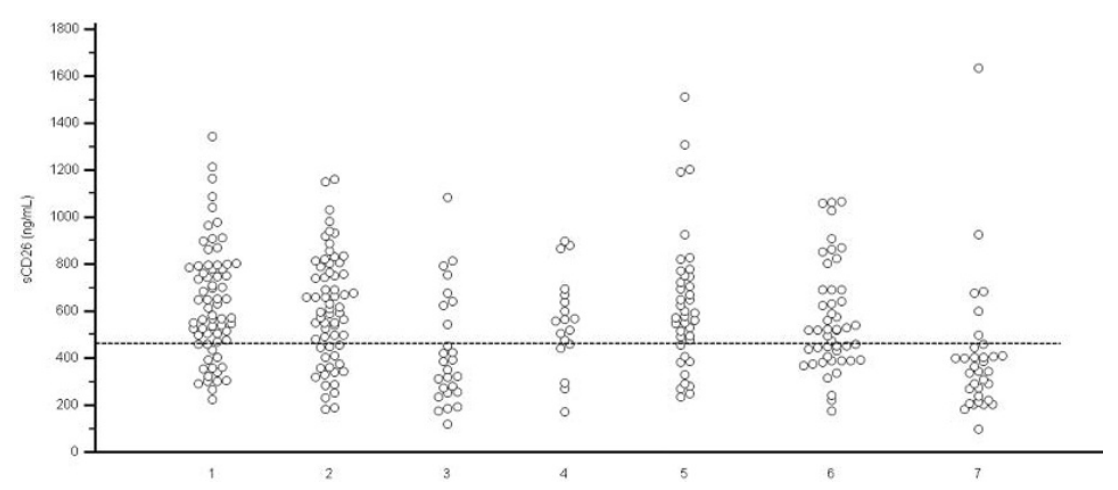

Figure 1 Dot plot representing the SCD26 concentration according to the colonoscopic diagnosis. Horizontal line: $460 \mathrm{ng} / \mathrm{mL}$ cut-off. 1: No colorectal findings $(n=68) ; 2$ : non-IBD ( $n=64) ; 3: \operatorname{IBD}(n=26) ; 4$ : hyperplastic polyps $(n=18) ; 5$ : non-advanced adenomas $(n=40) ; 6$ : advanced adenomas $(n=48) ; 7: C R C(n=33)$ 
Table 3: Chi-square and Fischer's exact analyses for the clinicopathological characteristics of polyps in relation to the sCD26 positivity

\begin{tabular}{|c|c|c|c|c|}
\hline Variable & $\begin{array}{c}\text { Mean } \pm \text { SD } \\
\text { sCD26 }(\mathrm{ng} / \mathrm{mL})\end{array}$ & $n s C D 26+/ n t$ & sCD26+ rate & $p$ \\
\hline \multicolumn{5}{|l|}{ Number } \\
\hline $1-2$ & $577.6 \pm 244.3$ & $28 / 84$ & 33.3 & 0.807 \\
\hline 3 or more & $624.6 \pm 256.1$ & $7 / 24$ & 29.2 & \\
\hline \multicolumn{5}{|l|}{ Size } \\
\hline$\leq 0.5 \mathrm{~cm}$ & $525.2 \pm 208.1$ & $11 / 32$ & 34.4 & \\
\hline $0.6-1 \mathrm{~cm}$ & $673.9 \pm 298.7$ & $6 / 28$ & 21.4 & 0.339 \\
\hline$>1 \mathrm{~cm}$ & $579.9 \pm 226.7$ & $18 / 48$ & 37.5 & \\
\hline \multicolumn{5}{|l|}{ Location } \\
\hline rectum & $549.0 \pm 190.0$ & $7 / 24$ & 29.2 & \\
\hline sigma & $617.1 \pm 273.7$ & $13 / 44$ & 29.5 & \\
\hline left colon & $571.7 \pm 194.5$ & $7 / 21$ & 33.3 & 0.475 \\
\hline transverse colon & $427.0 \pm 157.6$ & $4 / 6$ & 66.7 & \\
\hline right colon & $662.4 \pm 324.5$ & $4 / 13$ & 30.8 & \\
\hline \multicolumn{5}{|l|}{ Morphology } \\
\hline sessile & $592.8 \pm 264.4$ & $18 / 64$ & 28.1 & \\
\hline pediculated & $585.3 \pm 230.9$ & $15 / 39$ & 38.5 & 0.517 \\
\hline flat & $548.6 \pm 126.5$ & $2 / 5$ & 40.0 & \\
\hline \multicolumn{5}{|l|}{ Histology } \\
\hline hyperplastic & $560.4 \pm 201.3$ & $4 / 18$ & 22.2 & 0.413 \\
\hline adenomas & $597.2 \pm 256.1$ & $30 / 88$ & 34.1 & \\
\hline \multicolumn{5}{|l|}{ Detailed histology } \\
\hline hyperplastic & $560.4 \pm 201.3$ & $4 / 18$ & 22.2 & \\
\hline tubular & $605.3 \pm 259.9$ & $24 / 72$ & 33.3 & 0.358 \\
\hline villous & $612.6 \pm 305.8$ & $2 / 6$ & 33.3 & \\
\hline tubulovillous & $529.7 \pm 207.5$ & $4 / 10$ & 40.0 & \\
\hline \multicolumn{5}{|l|}{ Dysplasia } \\
\hline no dysplasia & $560.4 \pm 201.3$ & $4 / 18$ & 22.2 & \\
\hline $\begin{array}{l}\text { low-grade } \\
\text { dysplasia }\end{array}$ & $598.7 \pm 250.5$ & $27 / 83$ & 32.5 & 0.056 \\
\hline $\begin{array}{l}\text { high-grade } \\
\text { dysplasia }\end{array}$ & $562.9 \pm 293.1$ & $3 / 5$ & 60.0 & \\
\hline \multicolumn{5}{|l|}{ Adenomas } \\
\hline non-advanced & $633.9 \pm 286.9$ & $9 / 40$ & 22.5 & $0.048^{*}$ \\
\hline advanced & $566.7 \pm 225.8$ & $20 / 48$ & 41.7 & \\
\hline
\end{tabular}

SD: standard deviation; $n s C D 26^{+}$: number of individuals with sCD26 levels $\leq 460 \mathrm{ng} / \mathrm{mL}$; $n t$ : total number of individuals per group; sCD26+ rate: $S C D 26$ positivity rate. 
Table 4: Sensitivity and specificity for the sCD26 at the cut-off value of $460 \mathrm{ng} / \mathrm{mL}$

\begin{tabular}{|c|c|c|}
\hline Cohort & $n s C D 26+/ n t$ & Sensitivity $(95 \% \mathrm{Cl})$ \\
\hline CRC & $27 / 33$ & $81.8 \%(64.5-93.0)$ \\
\hline Advanced adenomas & $20 / 48$ & $41.7 \%(27.6-56.8)$ \\
\hline CRC and advanced adenomas & $47 / 81$ & $58.0 \%(46.5-68.9)$ \\
\hline Non-advanced adenomas and advanced adenomas & $30 / 88$ & $34.1 \%(24.3-45.0)$ \\
\hline Cohort & $n s C D 26-/ n t$ & Specificity $(95 \% \mathrm{Cl})$ \\
\hline No colorectal findings-no symptoms & $27 / 30$ & $90.0 \%(73.4-97.8)$ \\
\hline No colorectal findings & $54 / 68$ & $79.4 \%(67.9-88.3)$ \\
\hline $\begin{array}{l}\text { No colorectal findings, non-IBD, IBD, hyperplastic polyps, non-advanced and advanced } \\
\text { adenomas }\end{array}$ & $191 / 264$ & $72.3 \%(65.0-77.2)$ \\
\hline No colorectal findings, non-IBD, IBD, hyperplastic polyps and non-advanced adenomas & $163 / 216$ & $75.5 \%(68.5-81.0)$ \\
\hline
\end{tabular}

In our experimental setting we have also evaluated the diagnostic parameters for the sCD26. At the $460 \mathrm{ng} / \mathrm{mL}$ cut-off, the sensitivity and specificity for CRC versus noncancer groups were $81.8 \%$ and $72.3 \%$, respectively. This specificity is measured in the framework of symptomatic and asymptomatic patients bearing intermediate benign pathologies including non-IBD and IBD as well as polyps. When considering only asymptomatic individuals specificity increases to $90 \%$, which agrees with the results previously published by our group [15]; nevertheless a decrease in sensitivity will be expected in this context.

In an asymptomatic high-risk cohort of individuals with familial history of CRC or personal history of CRC or adenoma, Hazazi et al. [25] suggested the use of a quantitative immunochemical FOBT (iFOBT) for screening of high-risk individuals. Excluding individuals with anaemia, rectal bleeding and IBD, they reported a sensitivity and specificity for CRC of $100 \%$ and $85.3 \%$, respectively.

In the classical CRC screening studies in average-risk individuals, the gFOBT (guaiac-based) is extensively used, despite its wide range of sensitivity and specificity. The most common tests are the Hemoccult II (rehydrated or unrehydrated) and the Hemoccult SENSA', though the unrehydrated gFOBT is the one recommended for screening [26]. For the unrehydrated Hemoccult $\mathrm{II}^{\circ}$, the most accurate diagnostic parameters have been estimated with one-time testing on a Chinese [27] and an American populations [28]; in both, colonoscopy was performed to all individuals with positive or negative gFOBT results, reporting a sensitivity for CRC of 25 and $12.9 \%$, and a specificity of 80 and $95.2 \%$, respectively $[27,28]$. These studies reflect a poor sensitivity, although it is slightly improved with repeated annual or biennial testing (54-80\%), reaching up to $97.7 \%$ specificity $[29,30]$. On the other hand, a $50 \%$ sensitivity was obtained for a one-time rehydrated testing combined with sigmoidoscopy, though no specificity was reported, perhaps owing to an increase in the number of false positives due to rehydration [31].

When a highly sensitive test like the Hemoccult SENSA $^{\circ}$ is used, a $71-79 \%$ sensitivity is reached with single testing, and about $85 \%$ with multiple testing, with corresponding specificities of $86 \%$ and $95 \%$ [32,33]. However, these parameters are probably overestimated as these studies lacked colonoscopic examination of the negative cases.

Besides guaic-based FOBT, iFOBT has been recently offered as an alternative for average-risk screening. The studies reported up to date have shown that the iFOBT is more adequate for screening because of its high specificity since it detects human globin [26].

Throughout our study, evidence was gathered regarding the utility of the sCD26 in the detection of advanced 
adenomas. In separating CRC and advanced adenomas from all other groups, the sCD26 exhibited a 58.0\% sensitivity and a $75.5 \%$ specificity. For the same pathologies (CRC and advanced adenomas) in an asymptomatic highrisk cohort, Hazazi et al. [25] reported for a quantitative iFOBT a sensitivity and specificity of $65.3 \%$ and $87.5 \%$, respectively.

Regarding studies performed in average-risk individuals for the detection of CRC and advanced adenomas, gFOBT has shown a sensitivity of $10.8-14.3 \%[27,28]$ and a specificity of $79.2 \%$ [27], and consequently is not recommended for the detection of advanced lesions $[4,6]$. On the other hand, iFOBT showed a sensitivity of 33.1\% and a specificity of $97.5 \%$, though these parameters were given for only distal advanced neoplasm as compared to flexible sigmoidoscopy [25].

In relation to other experimental serum biomarkers for advanced adenomas, the CCSA-2 has shown a $97.3 \%$ sensitivity with a $78.4 \%$ specificity considering normal colonoscopy, hyperplastic polyps and non-advanced adenomas [13], whereas for CCSA-3 and -4 a combined sensitivity of $91.3 \%$ and a specificity of $78.7 \%$ was reported [14]. While sCD26 shows lower sensitivity, the specificity is equivalent even including patients with confounding pathologies such as IBD, which were not present in other studies.

Although sCD26 seems to perform adequately as a blood biomarker for CRC and advanced adenomas, independent of the frequent but intermittent bleeding unlike gFOBT or iFOBT, our study presents some limitations that should be considered: i) the symptomatic population included is at high-risk for CRC, with an elevated prevalence of colorectal pathology; ii) although no differences regarding age were detected, the age range of the patients differs from that recommended for screening; iii) the classification of the patients into the categories proposed resulted in several sub-groups with a small number of patients. Therefore, further research in a large population and under a screening context is desirable, along with the comparison to a sensitive gFOBT or iFOBT, and other experimental non-invasive methods.

\section{Conclusions}

Our results show that measurement of the sCD26 is a non-invasive and reasonably sensitive assay, which could be combined with others such as the faecal occult blood test, for the early diagnosis and screening of CRC and advanced adenomas. With this aim, we are currently initiating a multicentric, prospective, double-blinded study in an average-risk population, where the performance of the quantitive iFOBT and the sCD26 assay will be assessed and compared regarding the gold standard colonoscopy.
Competing interests

The authors declare that they have no competing interests.

\section{Authors' contributions}

LD: measurement of the sCD26 levels, data analysis, statistical evaluation, manuscript preparation. AMRP: data analysis, statistical evaluation, manuscript preparation. FJRB: Study design, coordination of the study. OJC: data analysis, manuscript preparation. DMA: Patient recruitment, collection of samples and clinical data. MPD: Study design, coordination of the study, final revision of the manuscript. All authors read and approved the final manuscript.

\section{Acknowledgements}

We thank the CHUVI Gastroenterology Unit, especially Dr. Pallarés-Peral, Dr. Martín-Granizo and Nini.

\section{Author Details}

1 Universidad de Vigo. Facultad de Biología. Departamento de Bioquímica, Genética e Inmunología. As Lagoas-Marcosende s/n. 36310 Vigo, Spain, 2Universidad de Santiago de Compostela. Departamento de Bioquímica y Biología Molecular. Edificio CIBUS, Campus Sur. 15782 Santiago de Compostela, Spain and ${ }^{3}$ Complejo Hospitalario Universitario de Vigo. Servicio de Digestivo. Calle Pizarro 22. 36204 Vigo, Spain

Received: 22 July 2009 Accepted: 28 June 2010

Published: 28 June 2010

\section{References}

1. Winawer SJ, Zauber AG, Ho MN, O'Brien MJ, Gottlieb LS, Sternberg SS, Wave JD, Schapiro M, Bond JH, Panish JF, Ackroyd F, Shike M, Kurtz RC, Hornsby-Lewis L, Gerdes H, Stewart ET, The National Polyp Study Workgroup: Prevention of colorectal cancer by colonoscopic polypectomy. The National Polyp Study Workgroup. N Engl J Med 1993, 329:1977-81.

2. O'Connell JB, Maggard MA, Ko CY: Colon cancer survival rates with the new American Joint Committee on Cancer sixth edition. J Natl Cancer Inst 2004, 96:1420-5.

3. Vogelaar I, van Ballegooijen M, Schrag D, Boer R, Winawer SJ, Habbema JD, Zauber AG: How much can current interventions reduce colorectal cancer mortality in the U.S.? Mortality projections for scenarios of riskfactor modification, screening, and treatment. Cancer 2006, 107:1624-33.

4. Smith RA, Cokkinides V, Brawley OW: Cancer screening in the United States, 2008: a review of current american cancer society guidelines and cancer screening issues. CA Cancer J Clin 2008, 58:161-179.

5. Benson VS, Patnick J, Davies AK, Nadel MR, Smith RA, Atkin WS: Colorectal cancer screening: a comparison of 35 initiatives in 17 countries. Int $J$ Cancer 2008, 122:1357-1367

6. Levin B, Lieberman DA, McFarland B, Andrews KS, Brooks D, Bond J, Dash C, Giardiello FM, Glick S, Johnson D, Johnson CD, Levin TR, Pickhardt PJ, Rex DK, Smith RA, Thorson A, Winawer SJ, American Cancer Society Colorectal Cancer Advisory Group, US Multi-Society Task Force, American College of Radiology Colon Cancer Committee: Screening and surveillance for the early detection of colorectal cancer and adenomatous polyps, 2008: a joint guideline from the American Cancer Society, the US Multi-Society Task Force on Colorectal Cancer, and the American College of Radiology. Gastroenterology 2008, 134:1570-1595

7. van Rijn JC, Reitsma JB, Stoker J, Bossuyt PM, van Deventer SJ, Dekker E: Polyp miss rate determined by tandem colonoscopy: a systematic review. Am J Gastroenterol 2006, 101:343-50.

8. Harewood GC, Wiersema MJ, Melton LJ III: A prospective controlled assessment of factors influencing acceptance of screening colonoscopy. Am J Gastroenterol 2002, 97:3186-94

9. Hewitson P, Glasziou P, Watson E, Towler B, Irwig L: Cochrane systematic review of colorectal cancer screening using the fecal occult blood test (hemoccult): an update. Am J Gastroenterol 2008, 103:1541-9.

10. Melle C, Ernst G, Schimmel B, Bleul A, Thieme H, Kaufmann R, Mothes H, Settmacher U, Claussen U, Halbhuber KJ, Von Eggeling F: Discovery and identification of alpha-defensins as low abundant, tumor-derived serum markers in colorectal cancer. Gastroenterology 2005, 129:66-73. 
11. Roessler $M$, Rollinger $W$, Palme $S$, Hagmann ML, Berndt $P$, Engel AM, Schneidinger B, Pfeffer M, Andres H, Karl J, Bodenmuller H, Ruschoff J, Henkel T, Rohr G, Rossol S, Rosch W, Langen H, Zolg W, Tacke M: Identification of nicotinamide $\mathrm{N}$-methyltransferase as a novel serum tumor marker for colorectal cancer. Clin Cancer Res 2005, 11:6550-6557.

12. Ayude D, Fernandez-Rodriguez J, Rodriguez-Berrocal FJ, Martinez-Zorzano VS, de Carlos A, Gil E, de la Cadena Paez M: Value of serum alpha-Lfucosidase activity in the diagnosis of colorectal cancer. Oncology 2000, 59:310-316.

13. Leman ES, Schoen RE, Magheli A, Sokoll LJ, Chan DW, Getzenberg RH: Evaluation of colon cancer-specific antigen 2 as a potential serum marker for colorectal cancer. Clin Cancer Res 2008, 14:1349-1354.

14. Leman ES, Schoen RE, Weissfeld JL, Cannon GW, Sokoll LJ, Chan DW, Getzenberg RH: Initial analyses of colon cancer-specific antigen (CCSA)3 and CCSA-4 as colorectal cancer-associated serum markers. Cancer Res 2007, 67:5600-5605.

15. Cordero OJ, Ayude D, Nogueira M, Rodríguez-Berrocal FJ, de la Cadena MP: Preoperative serum CD26 levels: diagnostic efficiency and predictive value for colorectal cancer. Br J Cancer 2000, 83:1139-1146.

16. Ayude D, Paez de la Cadena M, Cordero OJ, Nogueira M, Ayude J, Fernandez-Briera A, Rodriguez-Berrocal FJ: Clinical interest of the combined use of serum CD26 and alpha-L-fucosidase in the early detection diagnosis of colorectal cancer. Dis Markers 2004, 19:267-272.

17. Carvajal-Rodríguez A, de Uña-Alvarez J, Rolán-Alvarez E: A new multitest correction (SGoF) that increases its statistical power when increasing the number of tests. BMC Bioinformatics 2009, 10:209.

18. De Chiara L, Rodríguez-Piñeiro AM, Cordero OJ, Rodríguez-Berrocal FJ, Ayude D, Rivas-Hervada FJ, Páez de la Cadena M: Soluble CD26 levels and its association to epidemiologic parameters in a sample population. Dis Markers 2009, 27:311-316.

19. Chen W-T, Kelly T: Seprase complexes in cellular invasiveness. Cancer Metastasis Rev 2003, 22:259-269.

20. Boonacker E, Van Noorden CJF: The multifunctional or moonlighting protein CD26/DPPIV. Eur J Cell Biol 2003, 82:53-73.

21. Gorrell MD, Gysbers V, McCaughan GW: CD26: a multifunctional integral membrane and secreted protein of activated lymphocytes. Scand J Immunol 2001, 54:249-264.

22. Zisman $\mathrm{TL}$, Rubin DT: Colorectal cancer and dysplasia in inflammatory bowel disease. World J Gastroenterol 2008, 14:2662-2669.

23. Matusiewicz M, Krzystek-Korpacka M, Diakowska D, Grabowski K, AugoffK, Blachut K, Paradowski L, Kustrzeba-Wojcicka I, Piast M, Banas T: Serum sulfatase activity is more elevated in colonic adenomas than cancers. Int J Colorectal Dis 2008, 23:383-387.

24. Kumor A, Daniel P, Pietruczuk M, Malecka-Panas E: Serum leptin adiponectin, and resistin concentration in colorectal adenoma and carcinoma (CC) patients. Int J Colorectal Dis 2009, 24:275-281.

25. Hazazi R, Rozen P, Leshno M, Levi Z, Samuel Z, Waked A, Vilkin A, Maoz E, Birkenfeld S, Niv Y: Can patients at high risk for significant colorectal neoplasms and having normal quantitative faecal occult blood test postpone elective colonoscopy? Aliment Pharmacol Ther 2010 31:523-33.

26. Allison JE, Sakoda LC, Levin TR, Tucker JP, Tekawa IS, Cuff T, Pauly MP, Shlager L, Palitz AM, Zhao WK, Schwartz JS, Ransohoff DF, Selby JV: Screening for colorectal neoplasms with new fecal occult blood tests: update on performance characteristics. J Natl Cancer Inst 2007, 99:1462-1470.

27. Sung JJ, Chan FK, Leung WK, Wu JC, Lau JY, Ching J, To KF, Lee YT, Luk YW, Kung NN, Kwok SP, Li MK, Chung SC: Screening for colorectal cancer in Chinese: comparison of fecal occult blood test flexible sigmoidoscopy and colonoscopy. Gastroenterology 2003, 124:608-614.

28. Imperiale TF, Ransohoff DF, Itzkowitz SH, Turnbull BA, Ross ME: Fecal DNA versus fecal occult blood for colorectal-cancer screening in an averagerisk population. N Engl J Med 2004, 351:2704-2714.

29. Hardcastle JD, Chamberlain JO, Robinson MHE, Moss SM, Amar SS, Balfour TW, James PD, Mangham CM: Randomised controlled trial of faecaloccult-blood screening for colorectal cancer. Lancet 1996, 348:1472-1477.

30. Mandel JS, Bond JH, Church TR, Snover DC, Bradley GM, Schuman LM, Ederer F: Reducing mortality from colorectal cancer by screening for fecal occult blood. Minnesota Cancer Control Group. NEngl J Med 1993, 328:1365-1371.
31. Lieberman DA, Weiss DG: One-time screening for colorectal cancer with combined fecal-occult blood testing and examination of the distal colon. N Engl J Med 2001, 345:555-560.

32. Allison JE, Tekawa IS, Ransom LJ, Adrain AL: A comparison of fecal occultblood tests for colorectal-cancer screening. N Engl J Med 1996, 334:155-159.

33. Rennert G, Rennert HS, Miron E, Peterburg Y: Population colorectal cancer screening with fecal occult blood test. Cancer Epidemiol Biomarkers Prev 2001, 10:1165-1168.

Pre-publication history

The pre-publication history for this paper can be accessed here: http://www.biomedcentral.com/1471-2407/10/333/prepub

doi: 10.1186/1471-2407-10-333

Cite this article as: De Chiara et al., Serum CD26 is related to histopathological polyp traits and behaves as a marker for colorectal cancer and advanced adenomas BMC Cancer 2010, 10:333

\section{Submit your next manuscript to BioMed Central and take full advantage of:}

- Convenient online submission

- Thorough peer review

- No space constraints or color figure charges

- Immediate publication on acceptance

- Inclusion in PubMed, CAS, Scopus and Google Scholar

- Research which is freely available for redistribution

Submit your manuscript at www.biomedcentral.com/submit
C Biomed Central 